\title{
Analysis of Pre-Geodetic Maps in Search of Construction Steps Details
}

\author{
Gabriele Bitelli, Stefano Cremonini and Giorgia Gatta
}

Additional information is available at the end of the chapter

http://dx.doi.org/10.5772/46189

\section{Introduction}

Cartographic Heritage consists in the whole amount of ancient cartographic documents (not only maps, but also atlas, planispheres, globes, ...) the history has brought us, today perceived as a cultural value to be necessarily preserved due to its historical and geographical content as well as its artistic value. It is a great but often poorly known heritage, because usually ancient cartographic documents are kept in places closed to the public, and only occasionally they are proved valuable outside of specific research activities.

The recovery of ancient cartography is intended to save, and possibly to spread throughout a wide public, Cartographic Heritage, making use of the potential it offers. Unfortunately, ancient cartographic documents often suffer from preservation problems of their analogue support (an organic material, thus subject to wear), mostly due to aging. Therefore, the recovery of ancient cartography firstly consists in traditional restoration, intended to safeguard the analogue support against the damaging effects of time. Beside this, a recovery of the content of historical documents is also possible, carrying the cartographic document to a different support, usually a digital one. In such a way, regeneration of ancient cartography in a digital environment is an interesting way of Cultural Heritage preservation and valorisation.

Digital regeneration is not exhaust by the digitization step: modern digital techniques allow new chances of using the map information, which would be unachievable on an anague support. In particular, georeferencing and analysis of map deformations help in metric analysis of ancient cartography. In fact, usually the metric precision of an ancient cartographic document can be very different from that of a present map, due to an amount of deformations and errors that can be very high with respect to our standards. For example, graphical deformations can be induced by the old type of cartographic transformation (if one exists, it can be different from the modern ones), whereas other deformations can be due 
to an alteration in the analogue support; other errors can be recorded in the cartographic document, for instance errors that were made by the cartographer during survey or draft steps, or errors inherent to the surveying instruments at that time. In order to compare an ancient cartographic document to a modern one (usually a modern map used as reference), a georeferencing process is performed in a digital environment, assigning cartographic coordinates to a number of still existing and recognizable Ground Control Points (GCPs). This way, the native metric content of the map can be reproduced in the digital image, and furthermore an analysis of the existing map deformations is allowed. Thus, it becomes possible to understand the characteristics of metric precision of the original product (e.g. the projection type) in respect to the present reference cartographic base, as well as to evaluate and represent the degree of deformation recorded in the ancient document. The historical map, now in digital form, can be easily exploited and compared with other cartographic databases, thanks also to current web services; change analysis and analytical procedures can be performed through GIS applications.

This way, regeneration of ancient maps in digital form appears to be useful for many users: not only the public and institutions who collect them, but also experts who exploit this kind of documents to derive information for their studies, ranging from urban development to geomorphological or environmental topics. Many institutions today are digitalizing their cartographic heritage, in order to preserve and catalogue it and give online access to it (Adcock et al., 2004). On the evidence of growing interest in the argument, the International Cartographic Association (ICA) instituted in 2007 the "Commission on Digital Technologies in Cartographic Heritage", whose aim is to encourage digital approaches to cartographic heritage.

The present research would demonstrate the usefulness of the digital regeneration of ancient cartography; it provides an example of studies that can be performed after digital regeneration of ancient cartography, with a non-conventional approach mainly focused on technical considerations about the map-making procedures.

\section{Materials}

In this study, a set of three maps, depicting the northern coast of the Adriatic Sea along the Po river delta (South of Venice, Italy) at the end of the $16^{\text {th }}$ century, is analysed (Figure 1). The first two maps were both drafted in the year 1592, whereas the third one was drafted few years later (1599).

The maps represent a rare case where the authors of documents are known. The same cartographer, Ottavio Fabri, was author of the first map (hereinafter "F map") and co-author in the other two (hereinafter "P map" and "L map"), in which the main authors were Gerolamo Pontara and Bonaiuto Lorini, respectively. All of them were very famous landsurveyors in Renaissance Venice (Savi ed Esecutori delle Acque della Serenissima Repubblica).

The dimensions of these documents are very large, and their average scales range between about 1:12,000 and 1:13,000, not being constant throughout the entire maps. The original 
documents are kept today in the Venice National Archive (ASVe), and two of them (F and L maps) have been examined on site. The original documents are drawn on several watercolor papers stuck on canvas supports. For the aim of the present study, digital copies of the originals, made by ASVe, were used: high resolution (300-400 dpi) copies were derived from high quality scanning ( $\mathrm{F}$ and L maps), and a lower quality copy was derived from digitization of photographic images (P map), the original paper support being afflicted by wear problems. No images may be reproduced, in any form or by any means, without permission of the Venice National Archive; it is necessary to apply to the Photoreproduction Section of the Venice State Archive in order to obtain the release of copies. Granted for these reproductions: n. 81/2010.

A further fundamental tool of analysis was the book edited by the main author, Fabri, containing the description of the so called squadra zoppa (or squadra mobile, i.e. mobile square), a new topographical instrument probably invented and used by Fabri himself (Panepinto, 2009). That instrument was useful for performing every type of topographic measurement (i.e. heights, distances, depths) in urban and land surveying, and also for map drawing (reporting the measurements on the paper). Surprisingly, the handbook seems to be a powerful record of the author's whole technical experience originated by the surveying operations performed in the geographical areas depicted in the maps here studied (Figure 2). A copy of the book, today preserved at the Dore Library of the Engineering Faculty of the University of Bologna, has been examined on site (Fabri 1673).

\section{The reasons of the choice and the previous studies}

Even if the above mentioned existence of a textbook probably related to the chosen maps would not be taken into account, other strong motivations appear to exist to focus our analysis on those cartographic samples.

As these maps were made during the very short period between the years 1592 and 1599, i.e. the lapse of time immediately forerunning a series of very important works aiming at the Po river channel diversion, they stimulate a compelling geomorphological analysis (Cremonini 2007a; Cremonini \& Samonati 2009) focused on the easternmost peripheral areas that today no longer exist, due to erosional dynamics of seashore evolution developed during the last four centuries (Cremonini 2007b; Cremonini 2010). A further problem arises, due to the fact that the maps depict in a quite different manner the same landforms, although they appear to have been drawn in the same years by the same author or co-author (Ottavio Fabri). For these reasons the maps have already been studied from various viewpoints and metrically analysed in a digital environment (Bitelli et al. 2009, 2010), to try to overcome the merely qualitative comparison between the available maps.

Although the modern digital techniques, in particular georeferencing of the cartographic samples coupled with a study of the map deformations, help in metric analysis of ancient cartography, in pre-geodetic cartography studies specific analytical tools need to be used, e.g. in the step-by-step solution here proposed. 


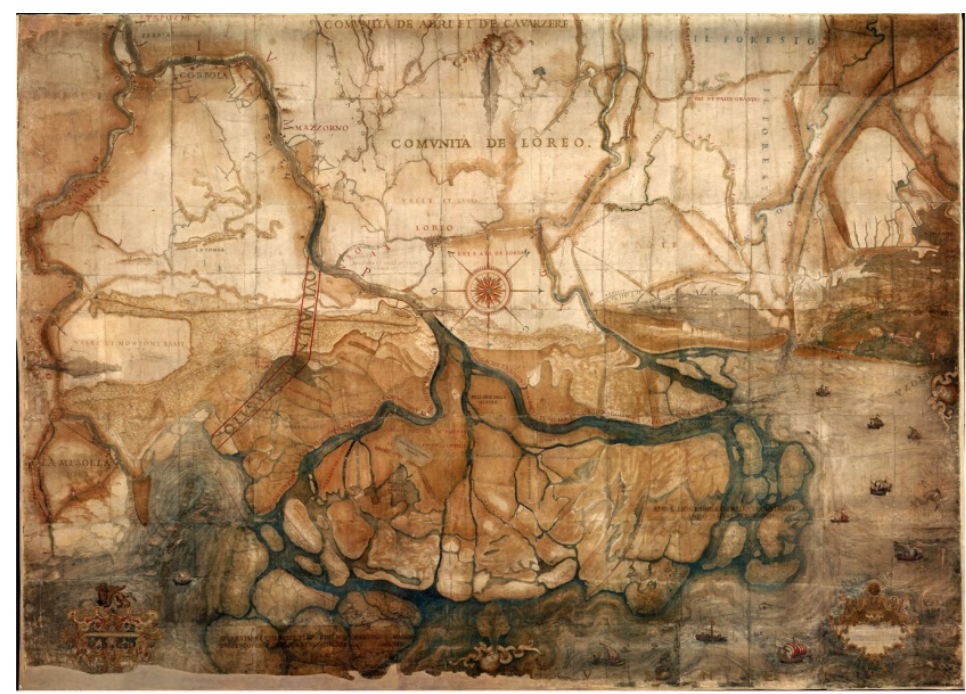

(a) F map

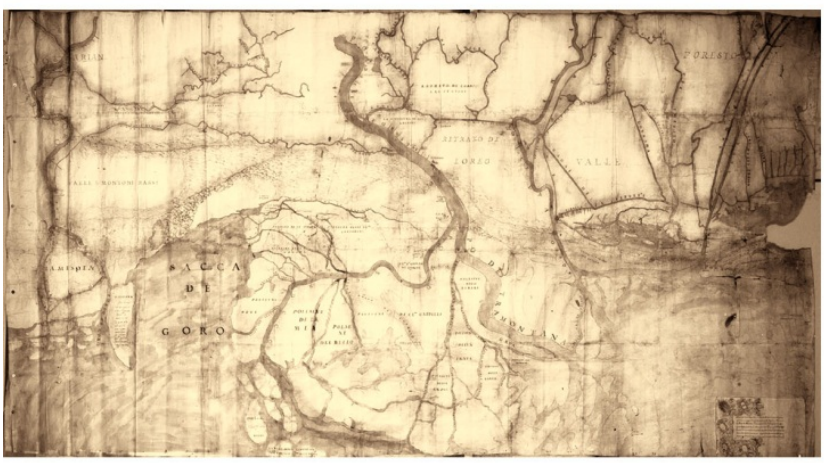

(b) P map

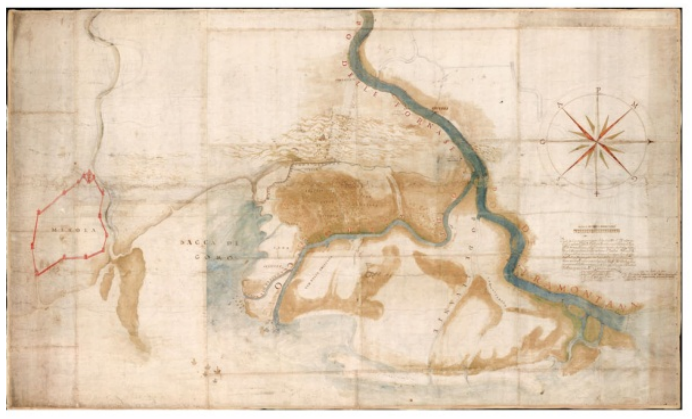

(c) L map

Figure 1. The three analyzed maps proportionally scaled (red bar $=1 \mathrm{~m}$ ): a) Delta del fiume Po, by Ottavio Fabri, 1592. Savi ed esecutori delle acque, serie Po, dis. 9bis. Size: about $3.5 \times 2.5 \mathrm{~m}$; b) Delta del fiume Po, by Gerolamo Pontara, Ottavio Fabri, 1592. Savi ed esecutori delle acque, serie Po, dis. 8. Size: about 2.9 x $1.6 \mathrm{~m}$; c) Delta del fiume Po, by Bonaiuto Lorini, Ottavio Fabri, Gerolamo Pontara, Alessandro Betinzuoli, Bartolomeo Montini, 1599. Savi ed esecutori delle acque, serie Po, dis. 10. Size: about 2.3×1.4 m. 


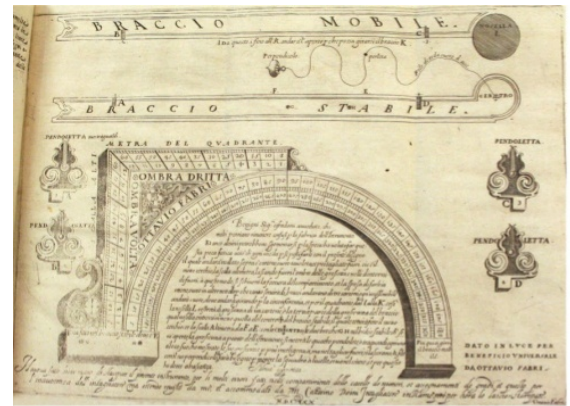

(a)

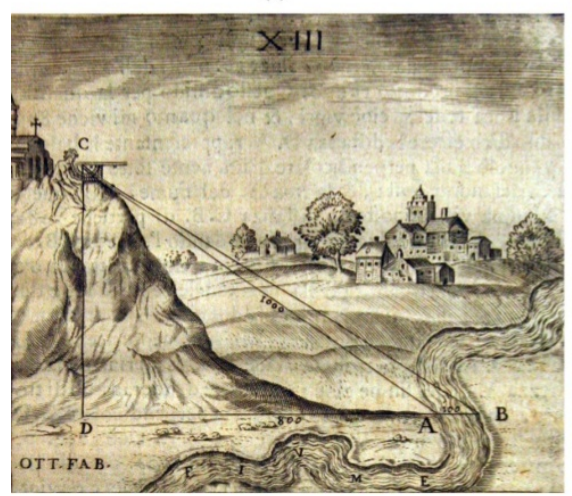

(b)

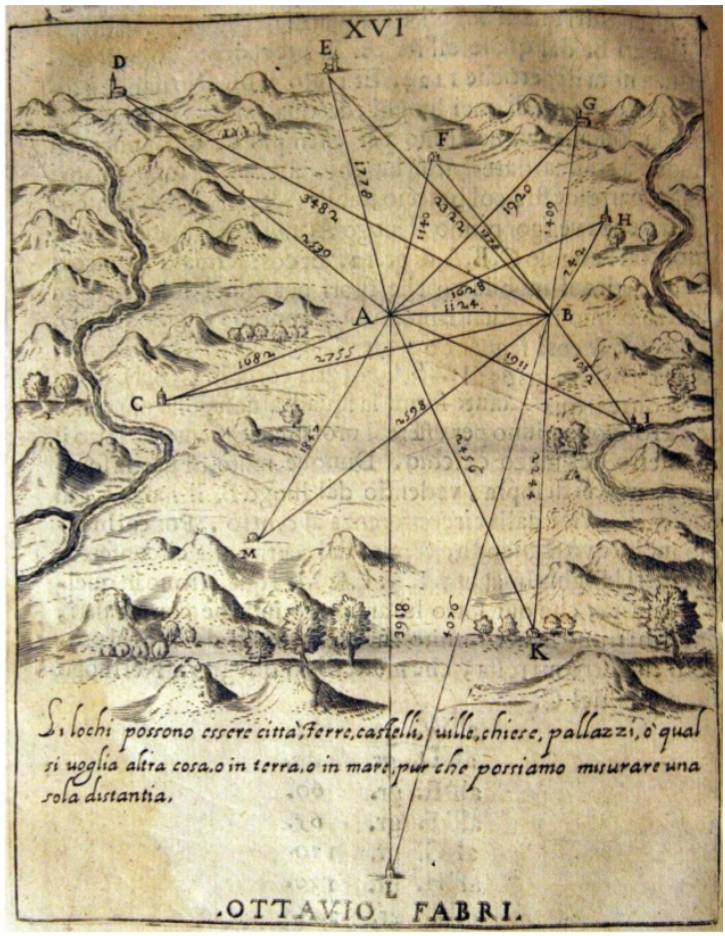

(c)

Figure 2. Images derived from O. Fabri, L'uso della squadra mobile (1673 edition, kept in the Engineering Faculty Library of the University of Bologna): (a) a picture of the squadra mobile; (b) measurement of river widths; (c) an exercise of forward intersection.

\subsection{The quantitative approach}

\subsubsection{Georeferencing}

Georeferencing is the technique of inserting a map into a reference system, usually a modern cartographic one. The process is performed by selecting in the ancient map a proper number (usually as large as possible) of peculiar points (GCPs, Ground Control Points), still existing today, and deriving their cartographic coordinates from the present cartography or a specifically designed survey. In the peculiar case of ancient cartography, the task can be very difficult or also impossible, because of the remarkable landscape evolution over time (Benavides \& Koster, 2006).

When a sufficient number of points is available, a one-to-one correspondence between the two set of control points lying on two different plane surfaces (i.e. points on the digital image of the ancient map, expressed in image coordinates, and reference points, expressed in cartographic coordinates) is established through a "best-fit" process, that finishes with the calculation of the transformation parameters. The number of involved parameters can varies 
with the transformations, each transformation requiring a different number of control points.

In fact, many kinds of georeferencing methods exist, and they produce results that can be qualitatively and quantitatively different. In particular, the georeferencing algorithms can be grouped in two different classes: global and local transformations (Balletti 2006; Boutoura \& Livieratos, 2006). In a global transformation (conformal, affine, projective, generic order polynomial) the unknown parameters are calculated for the whole area. On the other hand, in a local transformation (finite elements, morphing) the unknown parameters are calculated for a small area, defined by a small number of control points or close to each control point. The best georeferencing method probably do not exist, because the choice of a specific georeferencing method depends on the specific case (map characteristics, number of available GCPs, etc.) and on the purpose which the georeferenced images will be used for.

By means of a georeferencing process, the native metric content of the map being reproduced in the digital image, the historical map can be compared with the present cartography or other cartographies (also coeval ancient maps) in the same reference system. The process generates a new aspect of the ancient map, showing the typical deformation induced by its cartographic characteristics (and partly by the applied algorithm): in this way it is possible to understand the metric quality of the map representation (e.g. by means of the residuals errors associated to each single point, output by the geroreferencing process) and the projection features of the historical map, but also to perform many other kinds of analysis, e.g. studies related to change of the landscape.

In this specific case, after careful analysis of the three cartographic samples, a set of about 80 common GCPs, clearly identifiable also on the IGM (Italian Military Geographic Institute) topographic sheet, was recognized on the three ancient maps. It has to be stressed that in this phase a great deal of problems arose, concerning the basic characters of the points themselves (e.g. their planimetric precision, their graphic representation on the ancient maps, etc.), in addition to the difficulty in finding points that are still existing. North and East coordinates were attributed to each selected point according to the UTM-ED50 (fuse 33) grid. Different georeferencing methods were tested on the three map samples, and the most useful in order to compare them with the present landscape resulted polynomial transformations. In particular, the second order polynomial transformation resulted a good compromise between adaptation of the ancient maps to inland area details of the present landscape, on one hand, and constraint of deformations (indicated by the mean residual errors) throughout the maps, on the other (Bitelli et al. 2009).

Polynomial transformations coincide with a linear transformation (6-parameter affine) in the first order, and a non-linear one at higher degrees. A linear transformation corrects for scale, offset, rotation and reflection effects, whereas a non-linear transformation (for example, the $2^{\text {nd }}$ order polynomial transformation) corrects for non-linear distortions: the final result depends very much on the number of control points and their spatial distribution in the image plane.

In Figure 3 an overlay of the three maps on present high resolution satellite images (in Bing Maps $^{\mathrm{TM}}$ environment) is reported. The mean residual error (expressed as RMS, Root Mean 
Squared error) was about $588 \mathrm{~m}$ in $\mathrm{F}$ and $\mathrm{P}$ maps, ranging between 18 and 1,320 $\mathrm{m}$ in $\mathrm{F}$ map and between 85 and 1,650 in P map; it was more constrained in L map (mean: $452 \mathrm{~m}$; range: $29 \div 1,068 \mathrm{~m}$ ). The residuals appear to be lower in the map centre, whereas they increase in size in the peripheral areas. This is the classical border effect due to the polynomial transformation associated to the lack of reference points in the area. But in this specific case it can be supposed that the effect can be due also to other reasons, such as the survey technique locally adopted, accidental or intentional drawing errors, etc.

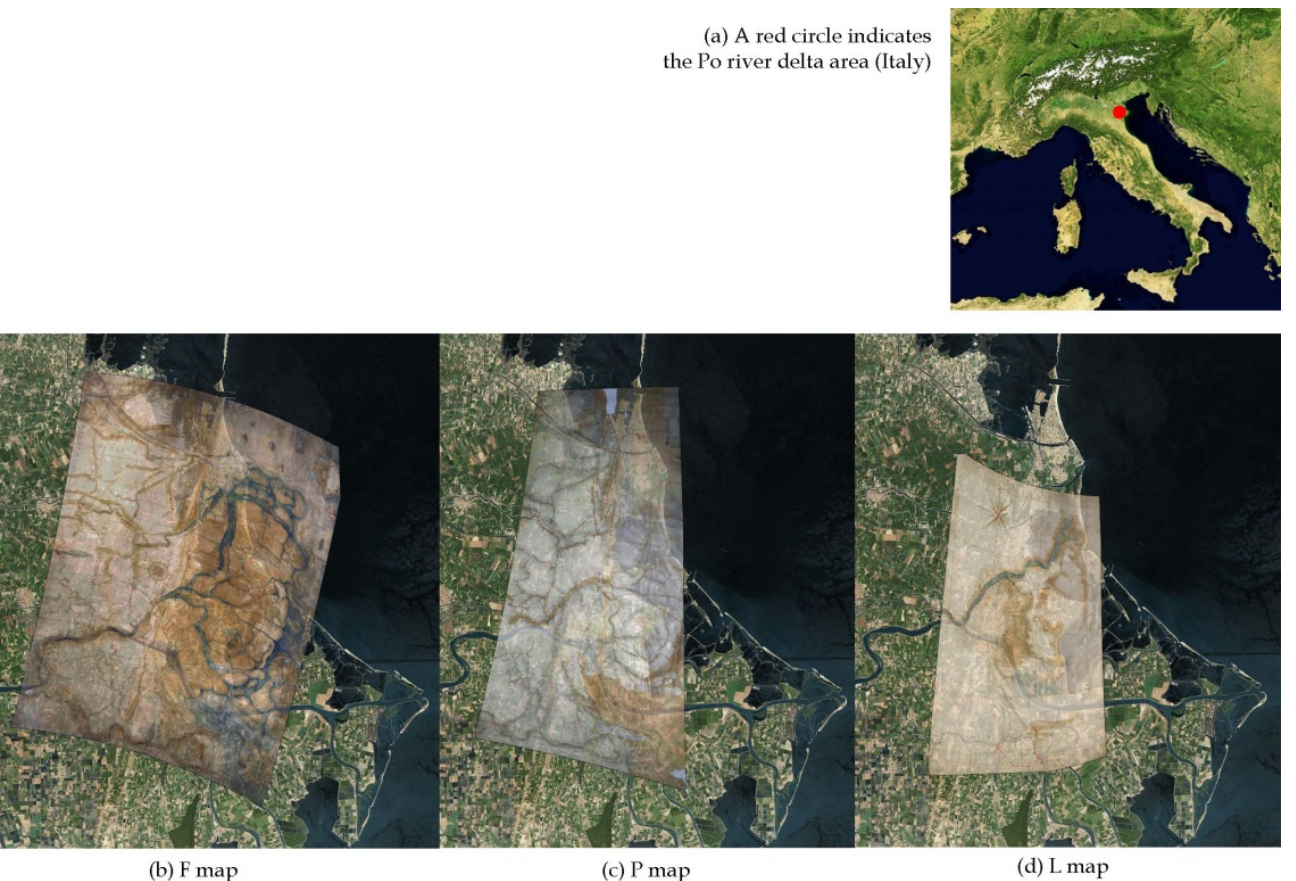

Figure 3. Overlay of the three ancient maps, georeferenced by means of a second order polynomial transformation, on present high resolution satellite images (in Bing Maps ${ }^{\mathrm{TM}}$ environment).

\subsubsection{Study of map deformation}

Comparing an ancient map with a present one allows evaluation and representation of the deformation degree of the former. Map deformations can be induced by physical alteration of the analogical support (a very frequent case for ancient maps) or by the old type of cartographic transformation (that frequently is unknown to us, and usually quite different from that used today and inducing less constrained deformations), or finally by surveying and drafting errors. Map deformations can be very high for ancient cartography; therefore, their assessment is essential in order to use the old samples for further studies (Livieratos, 2006). The assessment of map deformations consists in calculating some parameters from a comparison of the ancient map with a modern one as a reference (usually a present cartography to an appropriate scale, i.e. comparable with 
the scale of the ancient map), such as the rotation angle with respect to the present cartographic North, the scale variation throughout the map and the distortion of the present cartographic grid as resulting after its adaption onto the old map. The process is performed recognizing in the ancient map a proper number of still existing points, whose cartographic coordinates can be derived from the present cartography. A specifically designed software tool can result very useful for analysis of map deformations, allowing the calculation of all the aforementioned parameters and their subsequent drafting in an intuitive way (Jenny \& Hurny, 2011).

The study of map deformation characterising the cartographic samples here analysed showed scale factors quite variable throughout the maps, being slightly more homogenous in $\mathrm{F}$ map than in $\mathrm{P}$ map. The average scale resulting from the calculation was $1: 12,300(1: 14,300 \div 1: 10,300)$ and $1: 13,400(1: 16,600 \div 1: 10,200)$ in $F$ and $P$ maps, respectively. Notwithstanding this, the former map showed two severe anomalous variation areas near the northern and southern delta lobe corners (Bitelli et al. 2009). In particular, the northern gross deformation affecting F map is supposed to derive from a shift of the drawing, intentionally made by the author for unclear reasons. L map presented a bit more constrained scale factor (mean 1:11,200, range 1:13,200 $\div 1: 11,200$ ) and a smaller deformation than the other two, but it has to be taken into account that $\mathrm{L}$ map depicts a smaller area in respect to F and P maps (Figure 4). Moreover, the calculated rotation angles were $15.7^{\circ}, 8.9^{\circ}$ and $3.6^{\circ}$ for $\mathrm{F}, \mathrm{P}$ and $\mathrm{L}$ maps, respectively: they indicate an angular displacement of about $7^{\circ}$ between the first and the second map, and $12^{\circ}$ between the first and the third map.

In this specific case, where large areas, depicted in the maps, correspond to disappeared coastal (i.e. peripheral) belts, points suitable to be used as GCPs cannot be found in the present landscape, and the insertion of GCPs all around the deltaic area becomes obviously impossible. The metric analysis that was possible to perform on the set of maps highlighted gross deformations in all maps (especially in $\mathrm{F}$ and $\mathrm{P}$ maps). Notwithstanding some differences in the results showed by the maps, this analysis alone resulted insufficient to state which map has to be considered as the most faithful to the real asset of the ancient landscape.

Thus, a question still remains open: why does exist a family of so severe deformations?

\section{A second approach: a search for survey and draft step details}

Due to their representation scale and their aims, the maps could be regarded as true precursors of the modern "technical maps". But it is likely that these wide-sized maps were simply due to a scenic use of the products (e.g. for a good view during technical meetings held in the presence of political authorities) rather than to a real technical need. Unfortunately, up to now we possess neither the original field drafts nor the related field notebook that could allow us to do an enormous quality jump in the detailed inspection of the map generation process. Thus, any other analytical attempt must be taken into account to try to find out information about survey and draft phases. 

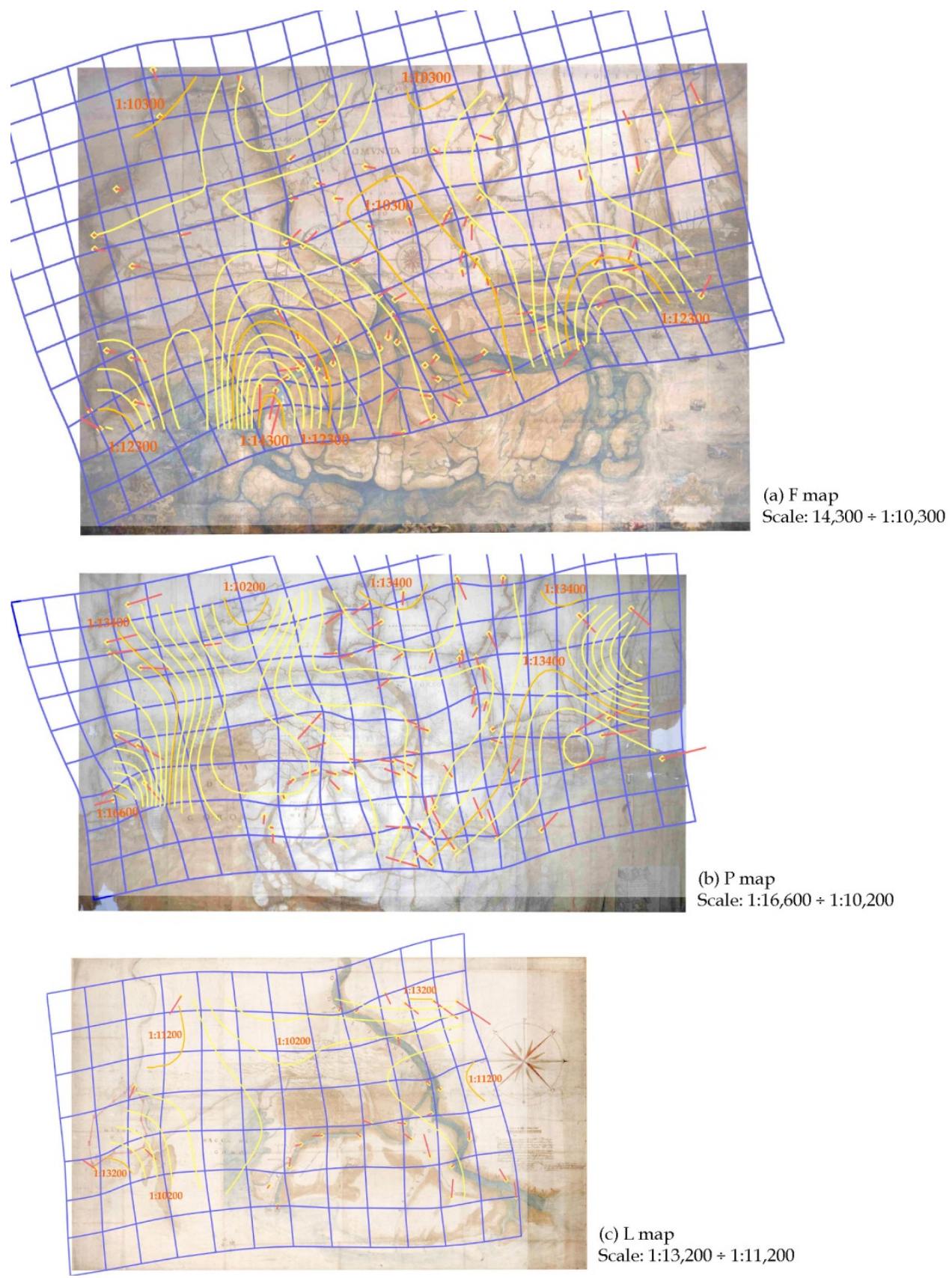

(c) L map

Scale: $1: 13,200 \div 1: 11,200$

Figure 4. Graphical results from a deformation analysis performed on the three maps (see Jenny \& Hurny 2011 for software description): in blue the UTM-ED50 grid (mesh size = $2 \mathrm{~km}$ ), in red the residual vectors on the GCPs, in yellow the scale isolines, in orange some values of the calculated map scale. 
In order to achieve this aim, late Renaissance land-surveying techniques (in particular the use of the squadra zoppa probably invented by Fabri himself) were studied and linked to technical signs preserved in the maps. Various signs, preserved either in the palimpsest of the maps or in their final drawing, were taken into account, and nine classes of evidence have been recognized (Bitelli et al. 2010): i) written information; ii) technical grids; iii) topographic measurements; iv) sighting tracks; v) "lost landmarks"; vi) preparing/correcting/updating drawings; vii) additional iconography; viii) unresolved questions; ix) restoration problems. The meaning of some signs is partly explained in the legend, whereas the meaning of others can be inferred by Fabri's methodological textbook. They will be briefly analysed in the next paragraphs.

\subsection{Written information}

In their cartouche, $\mathrm{F}$ and $\mathrm{L}$ maps state that the documents were made by merging some previous maps or other cartographic drawings and partly by means of direct topographic measurements (Figure 5). This kind of capital information helps us to understand that pregeodetic maps can be composite products (at least in the case of large scale maps), therefore they can be very difficult to be analyzed and their usual georeferencing could be partially inappropriate. L map cartouche states that different surveying techniques were adopted according to the different interest level of the various topographic domains (see Paragraph 4.3). Unfortunately, due to the low resolution of the digital image, on P map we cannot read the text content; moreover it seems to be an unfinished product regarding the cartouche decorations. Besides, the fundamental message is that the maps can be considered a sort of patchwork probably generated by merging some local maps, previously surveyed by the authors themselves or other colleagues, or partially ad hoc surveyed.

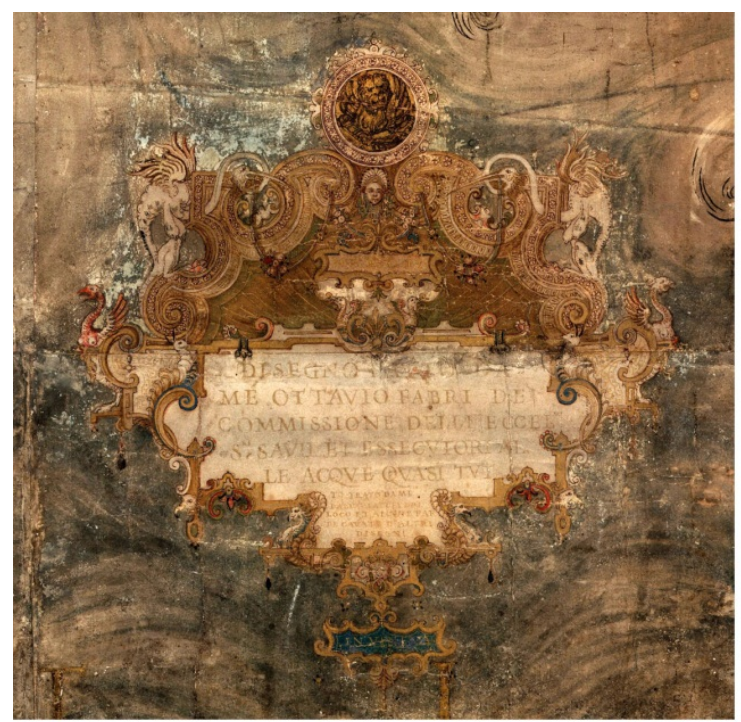

(a) F map

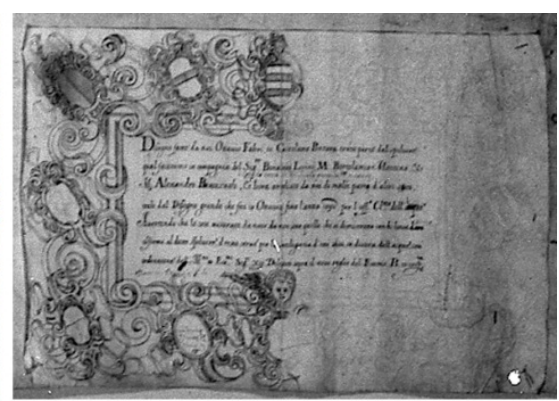

(b) P map

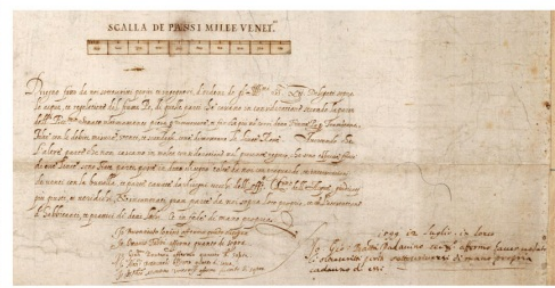

(c) L map

Figure 5. The cartouche in the three maps. 


\subsection{Technical grids}

A small-sized square mesh grid, drawn in charcoal, is distinctly visible on all the three maps (Figure 6a). The grids are characterized by different cell sizes: $10 \mathrm{~cm}$ on paper (about $1 \mathrm{~km}$ in world) in F map, $7.7 \mathrm{~cm}$ (about $1 \mathrm{~km}$ ) in P map, $4 \mathrm{~cm}$ (about $400 \mathrm{~m}$ ) in L map. In the first case, the cell size is exactly as long as half of the scale bar. This kind of grid covers the whole map and is drawn parallel to the North branches of the compass-card and to the map edges. Hence, the grid was probably helpful in assisting the transposition of the field-bearings onto the map support. We cannot state if the numbering of the grid squares (characterising the $\mathrm{P}$ map) had been used for this or other purposes, such as a mere scale reduction for copying.

Another very large sized grid exists on F map alone, and it is characterized by cells about five times larger than those of the previous one (Figure $6 \mathrm{~b}$ ). The grid orientation does not fit with the magnetic North, but coincides with a topographic direction clearly identifiable with the most rectilinear street reach located along a wide artificial canal (Rettinella) between the towns of Loreo and Tornova. It can be supposed that the canal was the starting baseline for the survey of the central part of the mapped lands, according to the forward intersection scheme showed by Fabri in his textbook (Figure 2c), assuming the still existing Loreo and Tornova bell towers as main reference points (Figure 2c, A and B points). Therefore, this second grid could have probably been used by the map-maker to draw on the map the azimuths measured in field and the sighting tracks toward all the noticeable points.

It is not possible to state whether the field survey strategy was the same for the other maps, as in them a similar large grid does not exist. If it was, the same baseline would have probably been used in P map (where it is clearly recognizable) but not in L map (where the Rettinella canal is roughly drafted in a marginal area of the map).

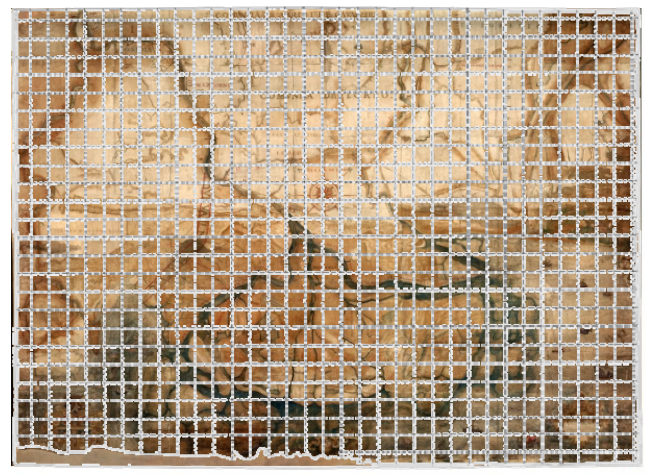

(a) The little-sized grid

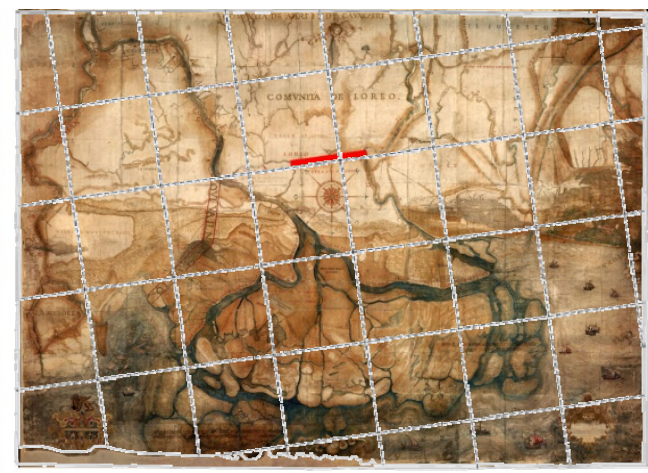

(b) The big-sized grid

Figure 6. Linedraw of the technical grids visible in F map, superimposed on the map. In (b) the Rettinella canal is highlighted in red.

\subsection{Topographic measurements}

Topographic measurements can be subdivided into three classes (Figure 7): 
i. explicit length measurements, which are clearly written as numbers of ancient Venice paces $(1$ Venice pace $=1.738674 \mathrm{~m}$, as stated in Martini, 1883), e.g. in the area of the Pertegado ditch, whose name properly means "measured";

ii. implicit length measurements, e.g. along the riverside where the points are graphically located in order to define the width and the geometry of the riverbanks;

iii. local bathymetric surveys and some selected riverbed transects, in particular at the river mouth of the Tramontana branch.

In the latter case, the mapmaker clearly highlighted which topographic reaches are the best surveyed, by means of red lines drawn onto the map. In those reaches pickets were certainly located and their related distances measured. According to that, each of these points had to be further sighted from a standpoint lying on the opposite riverside.

Therefore, this class of evidences states the fundamental technical character of the maps as a whole or for some selected subareas.

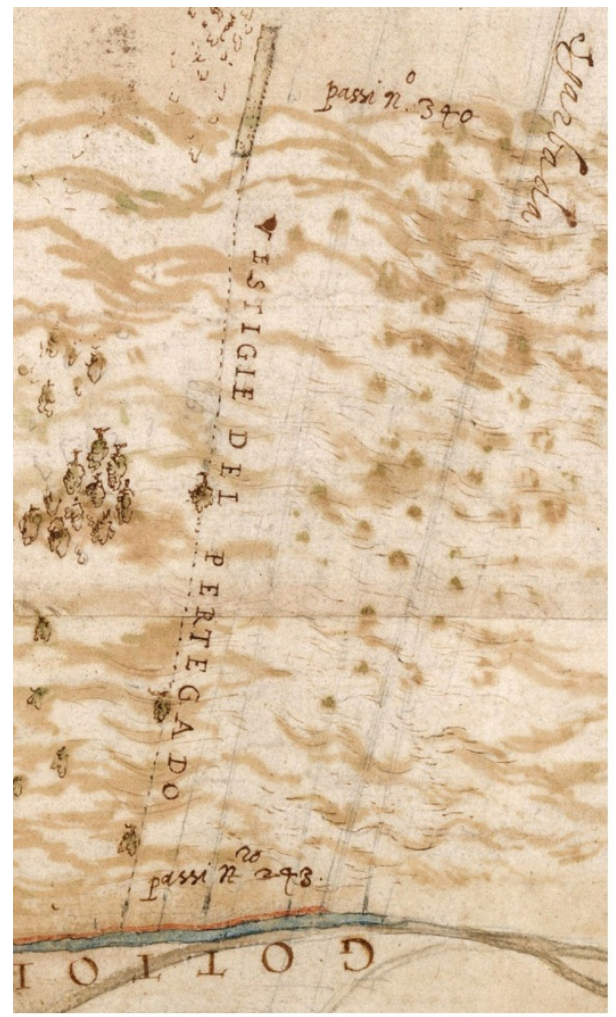

(a) Explicit length measurements

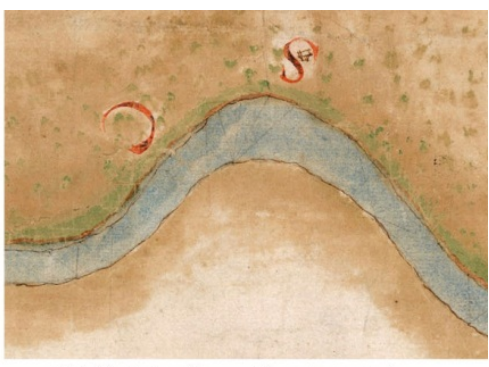

(b) Points along the riverside and red reaches

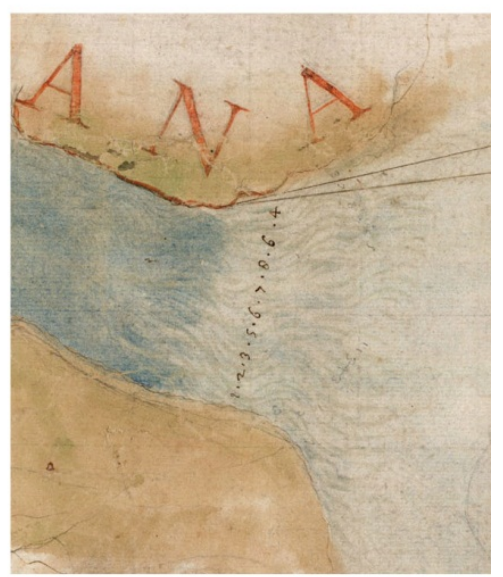

(c) Local bathymetric surveys

Figure 7. Topographic measurements in L map. 


\subsection{Sighting tracks}

Some sighting tracks (sometimes identified by a number and a letter) are clearly visible, in particular in L map (Figure 8) and occasionally in P map. These tracks are preserved in sea areas lying between the Po delta and the continental coast reaches in the northern and southern part of the delta lobe. They try to define the correct distance existing between selected points lying on the fast-prograding delta coast and well-visible landmarks lying on the opposite coastal domain, e.g. Mesola defense towers and Chioggia bell towers. The length of the longest tracks is about $10 \mathrm{~km}$, a plausible value for field surveys in marine environment free of the vegetative mantle (thus characterized by a good inter-visibility of the points).

This kind of information could suggest the author's need to control the existence of gross errors in the conclusive survey phase.
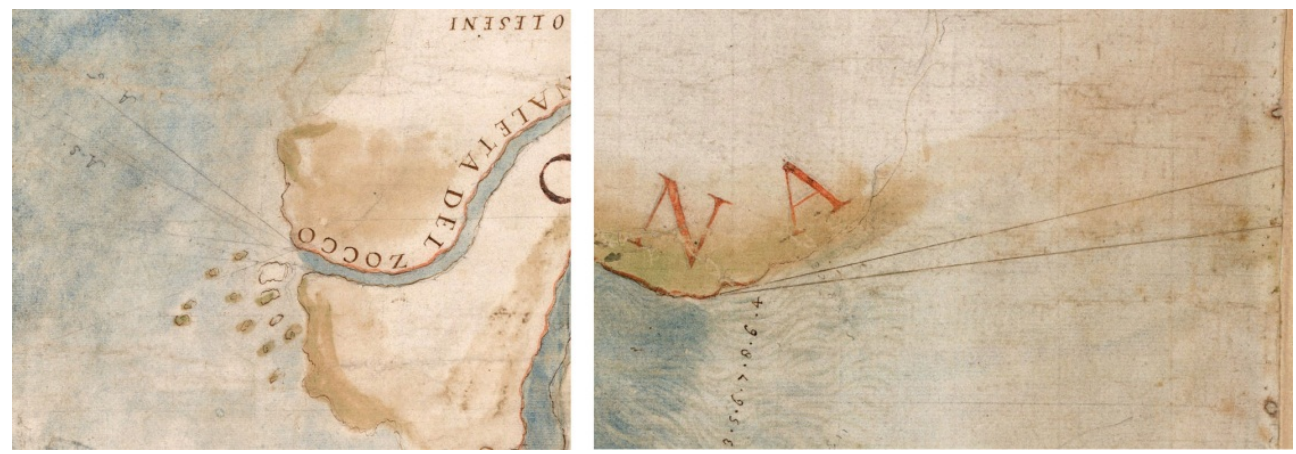

Figure 8. Examples of sighting tracks visible in L map.

\section{5. "Lost landmarks"}

Other signs of unclear value are visible in F map. They are not preserved in today landscape, thus they should have not been true landmarks (Figure 9): for this reason we prefer to use the term lost landmarks for their identification. They consist in few small crosses and a large one located at the diffluence point of two river branches of the Po di Levante. The large cross was probably a real reference-point as this object gave its name to a salt marsh (Polesine de la Crose) and to a still preserved building. The small crosses are located in desert areas of the $\mathrm{E}$ and SE realms of the delta lobe, along a red double curvilinear track. The meaning of the curvilinear tracks has been deduced from the comparison with another map of the same area dating back to the year 1608: they define the boundaries of the lands confiscated by the Venice Government in 1588.

This class of evidences highlights how difficult the ancient land surveying was, due to lacking of tall and fixed benchmarks in high-speed changing areas. On the other hand, it highlights how much important, from an economic point of view, those new generated areas were for the local government, thus suggests a possible reason to start the survey 
works. A question remains open: were those landmarks the only ones existing or are they simply a selected set?

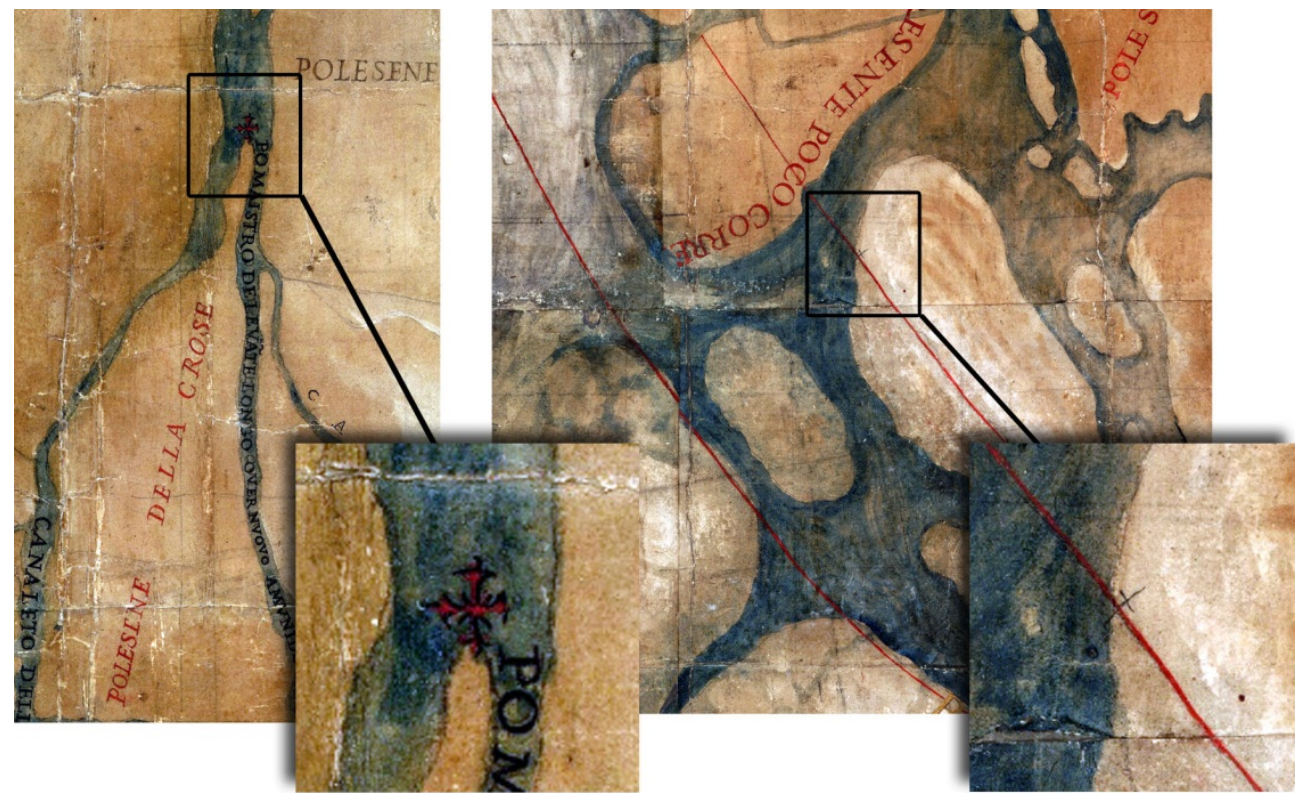

(a) The large cross (b) A little cross

Figure 9. Signs of unclear value (lost landmarks) drawn in F map: a large cross at the diffluence point of two river branches, and a small cross lying on a red double curvilinear track.

\subsection{Preparing/correcting/updating drawings}

In each map, former drawings of topographical elements can be observed at various places. They represent details of riverbeds or local ways and were probably drawn as a first approximation of topographic elements. In the last definitive drawing, they appear corrected in their shape and/or location (Figure 10).

It may be believed that they represent the first attempt at defining the topographic design in those parts of the map derived from previous cartographic documents (as stated in the cartouche of F and L maps, see Paragraph 4.1). In some other cases, these kinds of correction probably referred to real environmental changes developed over time, as in the case of the minor branches of the Scirocco Po branch near Mea place (e.g. in P map, see Figure 10a).

It is difficult to conceal that these features represent an interpretative problem, as they suggest a high approximation degree in the drafting of the topographic details.

\subsection{Additional iconography}

In F map a very particular detail consists in a number of appliqués showing ancient vessels (Figure 11a). It was possible to notice such a detail only thanks to a direct consultation of the 
original analogical document in ASVe. We could ask ourselves why these symbols were stuck on the map and not directly drawn on it, whereas a very beautiful fish image (a sturgeon) was drawn in front of the Tramontana branch mouth (Figure 11b).

The question is not out of sense because it can suggest chronological problems, also related to tracking of the reference grid (Figure 11a).

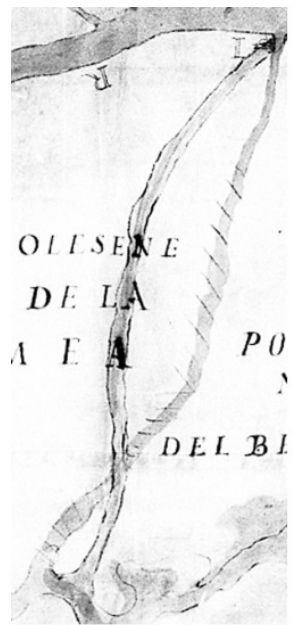

(a) P map

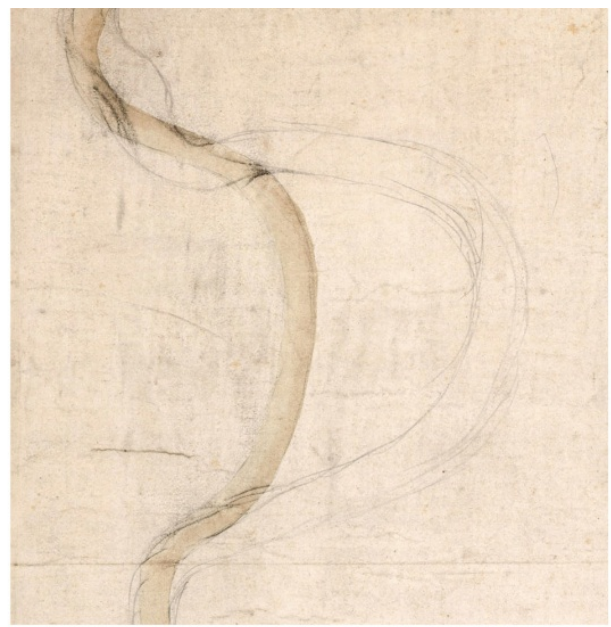

(b) L map

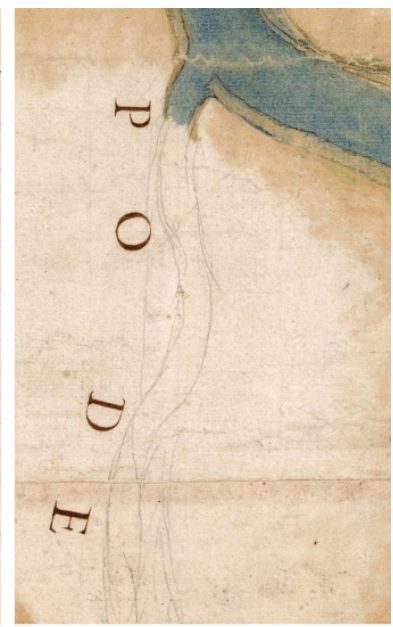

(c) L map

Figure 10. Examples of updating riverbed details in $\mathrm{P}$ and $\mathrm{L}$ maps.

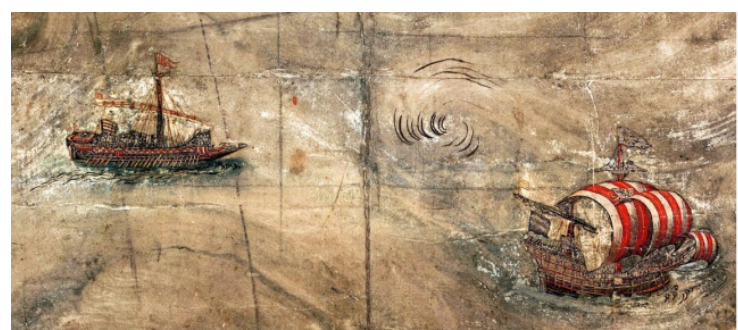

(a) Appliqués of ancient vessels

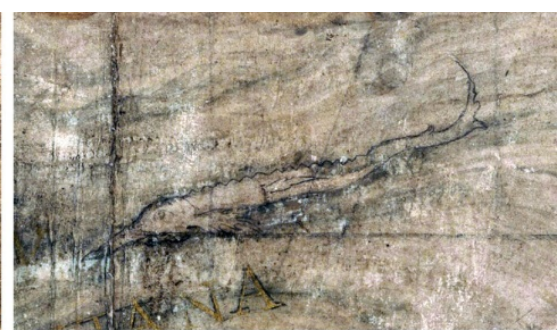

(b) Image of a sturgeon

Figure 11. Examples of additional iconography in F map: appliqués showing ancient vessels and the image of a sturgeon.

\subsection{Unresolved questions}

Each map derives from the assemblage of single sheets on a canvas, clearly identifiable thanks to the visible seams (Figure 12). As a result, the homologue tracts of the drawing do not always fit well together. Hence, a problem arises concerning the age of the last sheet assemblage: does the assemblage date back to the original edition of the map or to a more recent one, being related to a series of restorations? 


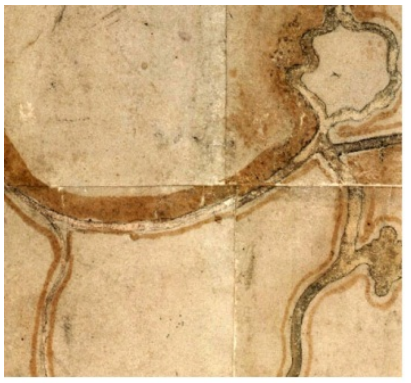

(a) F map

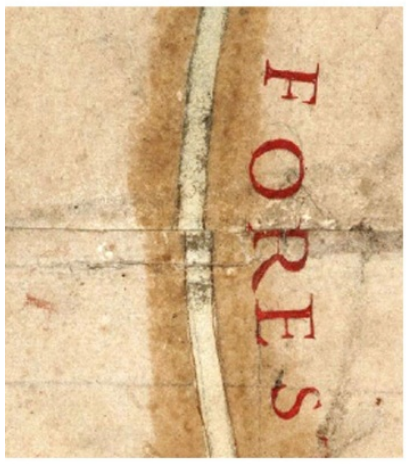

(b) F map

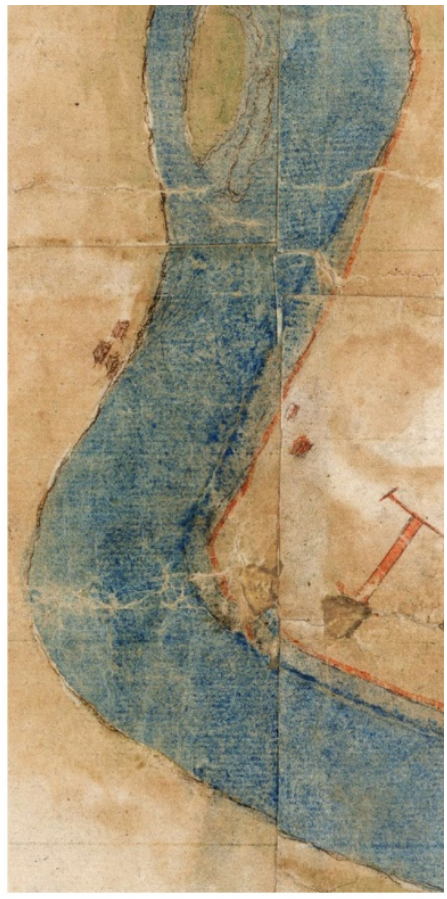

(c) L map

Figure 12. Visible seams in F and L maps, due to the assemblage of single sheets on the canvas: the homologue tracts of the drawing do not always fit exactly together.

As what we can see today is the product of the long lifespan of the maps, a fundamental question arises concerning type, number and entity of the restorations performed on them. Each restoration probably slightly changed the map almost imperceptibly. This may be true also for the smallest details, and it could partially deny the possibility of performing a correct diachronic study of the original document.

\section{A discussion and a proposal}

Notwithstanding some still open questions, the whole set of the discussed details highlights a very interesting class of information related to the hidden steps of pre-geodetic map construction. In particular, these details highlight the presence in the map of areas surveyed by means of different methodologies. This fact can explain the different entity of georeferencing residuals characterising different areas as well as the presence of high deformations in some particular areas rather than in others. The use of different survey methodologies can be due to various reasons, such as different levels of interest in the representation of different zones (e.g. areas confiscated by the Venice government, or areas planned for the forthcoming Po river diversion), or difficulties in surveying some others (e.g. areas too far from a selected reference baseline, or without well-recognizable 
landmarks), or, finally, the involvement of more than one person in the surveying works. As explicitly stated in some cartouches, the morphology of some depicted land areas can have been taken from other previously developed cartographies; those areas are not explicitly highlighted by the authors, but it is possible to infer their locations by excluding zones where explicit signs refer to specific surveying techniques (i.e. sighting tracks, length measurements, red reaches, bathymetric surveys). It can be hypothesized that some topographical elements characterized by former drawings (e.g. in L map, see Paragraph 4.6) were derived from previous cartographic documents. In fact, some visible former drawings (e.g. Figure 10b) are placed in peripheral areas where residuals from the georeferencing process are higher than those obtained in other areas of the map.

Other kinds of former drawings probably refer to corrections made by the authors over time: they can denote real environmental changes in shape and/or location of the topographic elements, or also intentionally-made corrections. The first ones can be highlighted by a roughly deletion of previously drawn elements (see Figure 10a), whereas the second ones seem to have been hidden by the authors by means of a brush stroke covering. This is the case of an astonishing map "correction", well recognizable in F map (Figure 1a), probably done at an early drawing stage. For that detail it was thought that the northern cluster of islands had been northward-shifted by the author for an unclear reason. This could be supported by both the comparison with the other maps and the existence of a wide area with no clear topographic detail lying immediately south of the delta coast. Hence, a possible verisimilar original map appearance could be that shown in Figure 13: it is a true "false case", generated by means of a simple "surgical" operation performed in a digital environment, in the opposite direction compared to the alleged author intervention. It must be noticed that the southward-shifted cluster of islands coincides perfectly in its morphology with the part of islands remained untouched.

The above described operation could now be attempted in all the other areas of $\mathrm{F}$ map with already evidenced anomalies (Cremonini \& Samonati, 2009), allowing a complete regeneration of this ancient map. This could be an interesting way of approaching the study of pre-geodetic maps.

\subsection{Georeferencing of the "false case"}

The presence of intentionally-made corrections could explain why some areas, differently represented in $\mathrm{F}$ map in respect to $\mathrm{P}$ map (whereas in $\mathrm{L}$ map the represented land is smaller), maintain an unclear post-georeferencing deformation in $\mathrm{F}$ map. In order to demonstrate this assumption, a comparison of the new product (the "false case") with present cartography via modern georeferencing methods was made. In Figure 14 the overlay of the "false case" on present high resolution satellite images (Bing Maps ${ }^{\mathrm{TM}}$ environment) is reported; the map was georeferenced by means of a second order polynomial transformation, as done for the original map (see Figure 3b). An analysis of residuals of georeferencing could be the best way to check a real improvement in metric quality of the new cartographic product in respect to the original one, but in this particular 
case the test results impossible, due to the lack of still existing reference points in the deltaic area. Therefore, only a comparison between coeval maps is allowed. In Figure 15 the comparison between the "false case" and the georeferenced P map (by means of a second order polynomial transformation) is showed. In this case, the increase in correspondence for the northern cluster of islands details between the two maps is very high (see Figure 15b). For the purpose, a vectorization of $\mathrm{P}$ map was used in order to better visualize the overlay. Unfortunately, L map covers a smaller land area, and other coeval maps depicting the same deltaic area do not appear to exist: thus, the comparison with $\mathrm{P}$ map only is possible and significant.

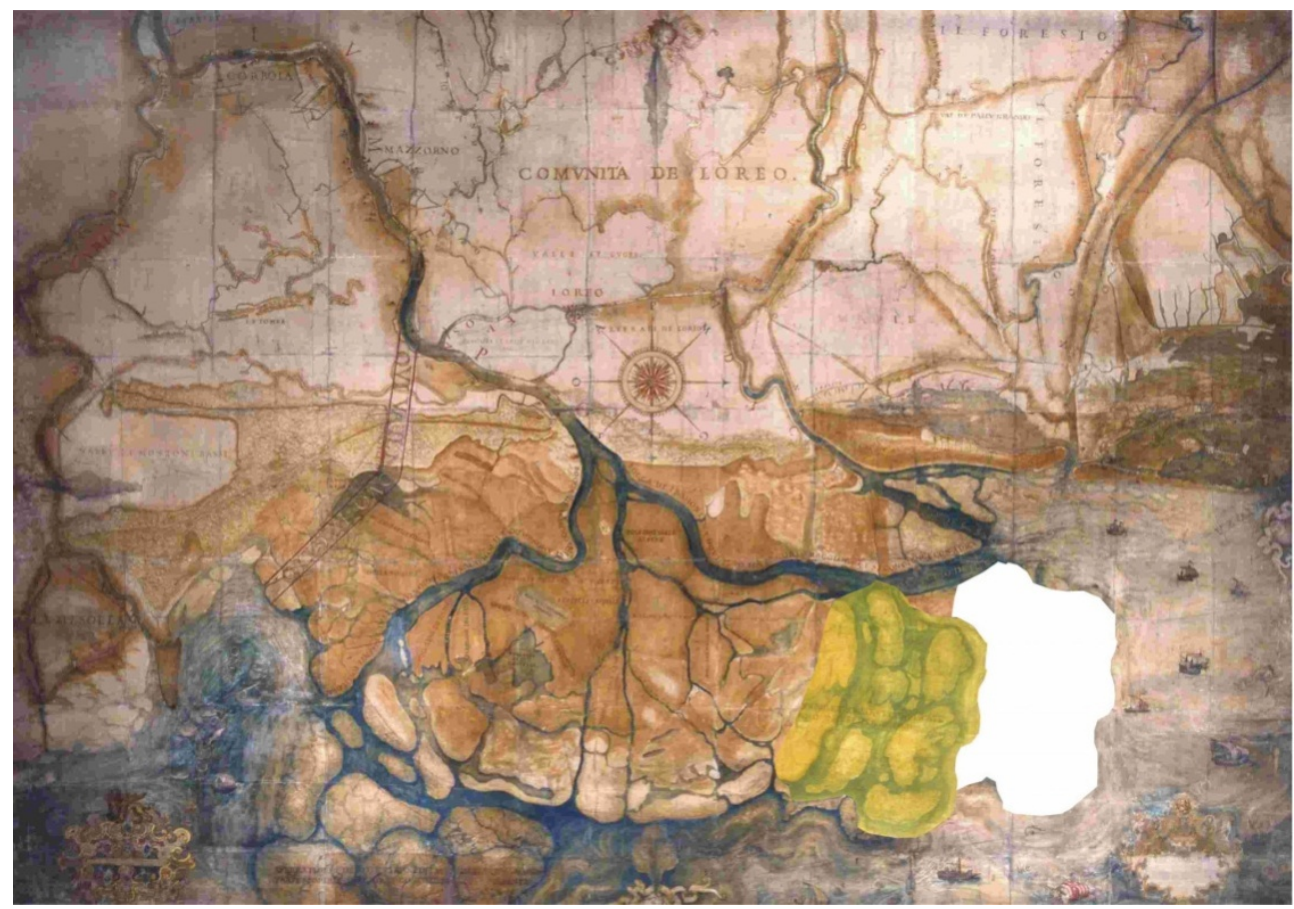

Figure 13. A true "false case": the first attempt at restoring the possible original appearance of the former real map configuration before the alleged author intervention (in yellow the part translated and rotated from the white original location). North is right.

\subsection{Towards possible future developments}

The quite simple analysis above proposed could be considered as a stimulus toward a new way of approaching the study of pre-geodetic cartography: an approach capable to deeply enter the factual map genesis processes. In fact, a mere mathematical approach could not be satisfying for situations similar to the above discussed. As shown in Figures 16 and 17, the attempt of mutual comparison among the georeferenced coastline locations for the three studied maps could remain widely questionable. In these case, in fact, a gross discrepancy in 
the location of the same coastline ( 2 up to $3.5 \mathrm{~km}$ ) in the same year 1592 remains between $\mathrm{F}$ and $\mathrm{P}$ maps, therefore neither reliable coastal erosion rates (Figure 16) nor a correct pointby-point response of the ancient beach line to the wind-induced long shore currents (Figure 17) can be believably proposed.

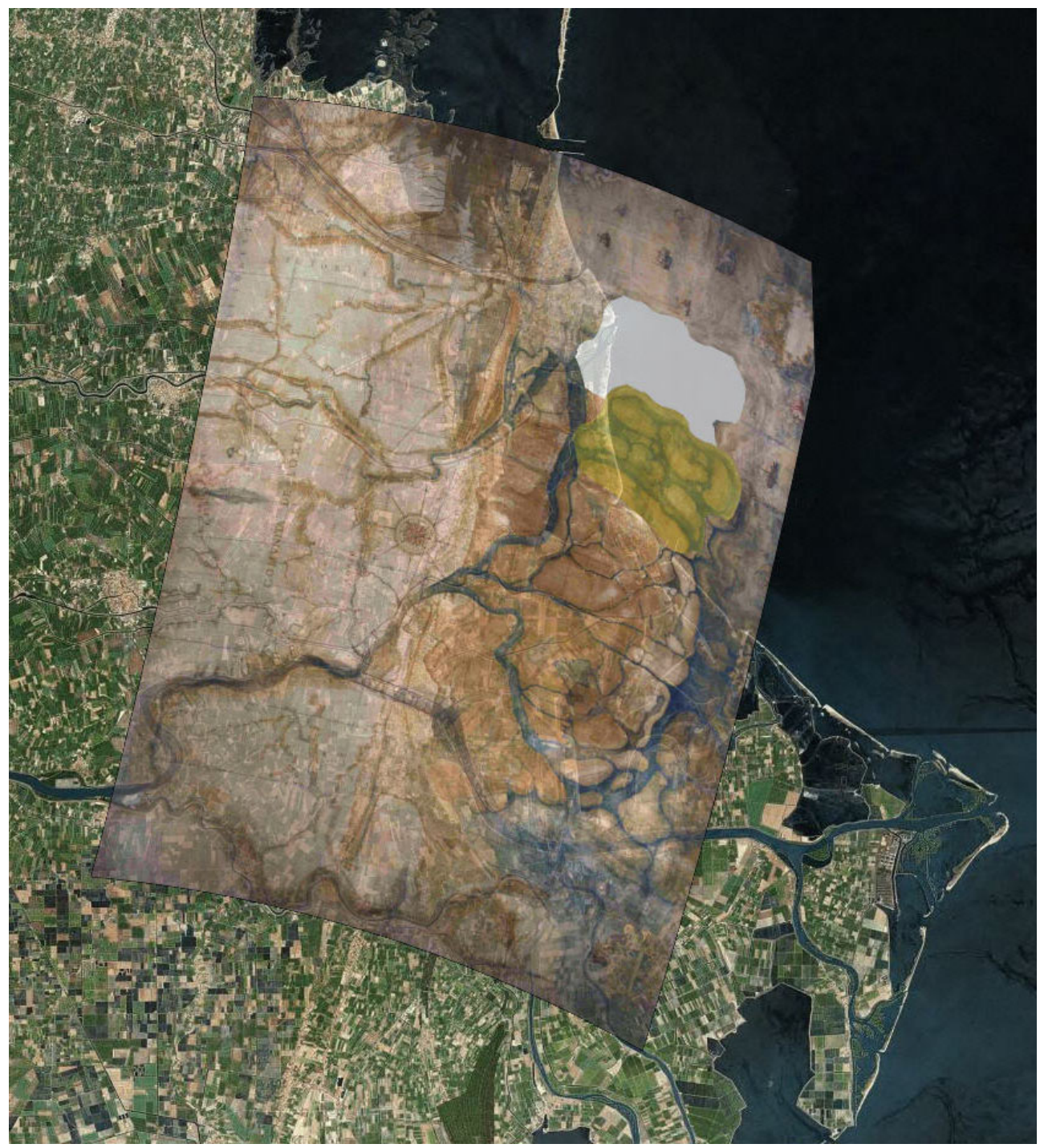

Figure 14. Overlay of the "false case", georeferenced by means of a second order polynomial transformation, on present high resolution satellite images (Bing Maps ${ }^{\mathrm{TM}}$ environment). 


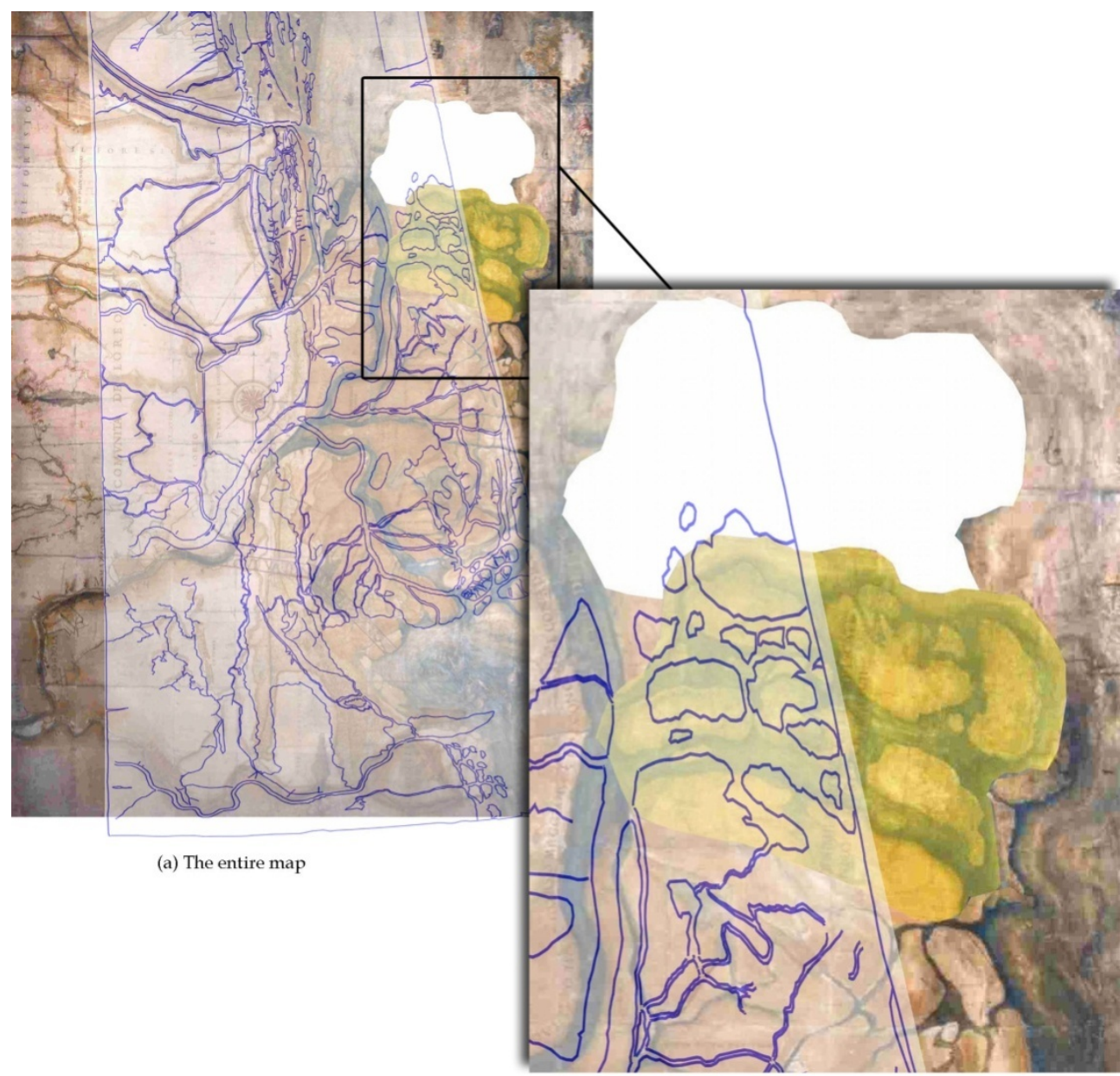

(b) A detail

Figure 15. Overlay of a georeferenced vectorization of the P map (in blue) on the "false case".

To overcome this impasse, a complex methodological approach would be adopted: it would be capable to check and take into account the metric information still preserved in the ancient maps, though partially hidden, and finally to regenerate the lacking topographic details or relocate them in a more reliable way. Only at that stage, a new phase of the study, based on a new and more reliable ancient map, will be triggered for various classes of researchers. 


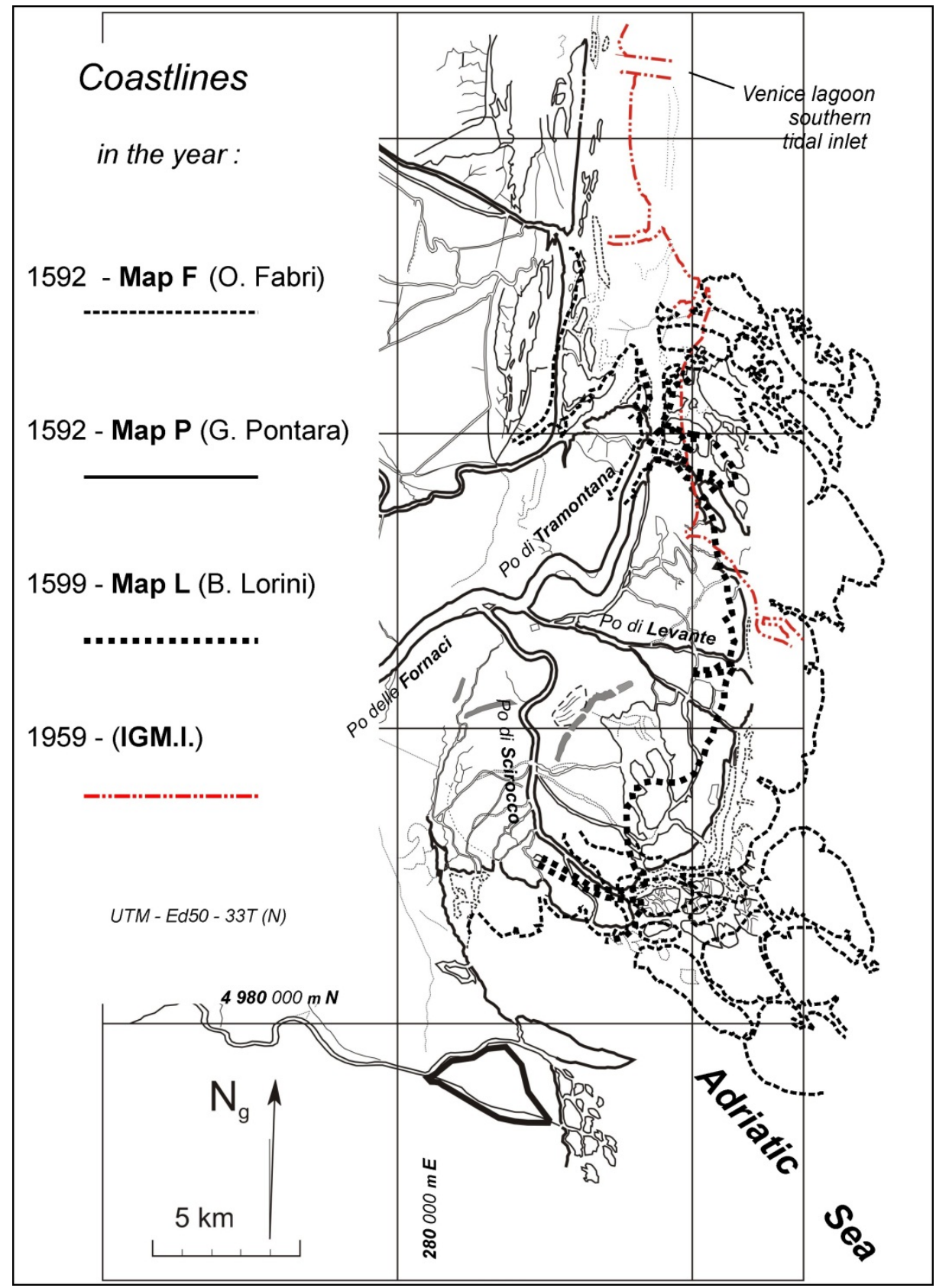

Figure 16. Coastline shape from the georeferencing of F, P and L maps on Italian modern cartography (Cremonini and Samonati, 2009; Cremonini 2010, Fig. 2). 


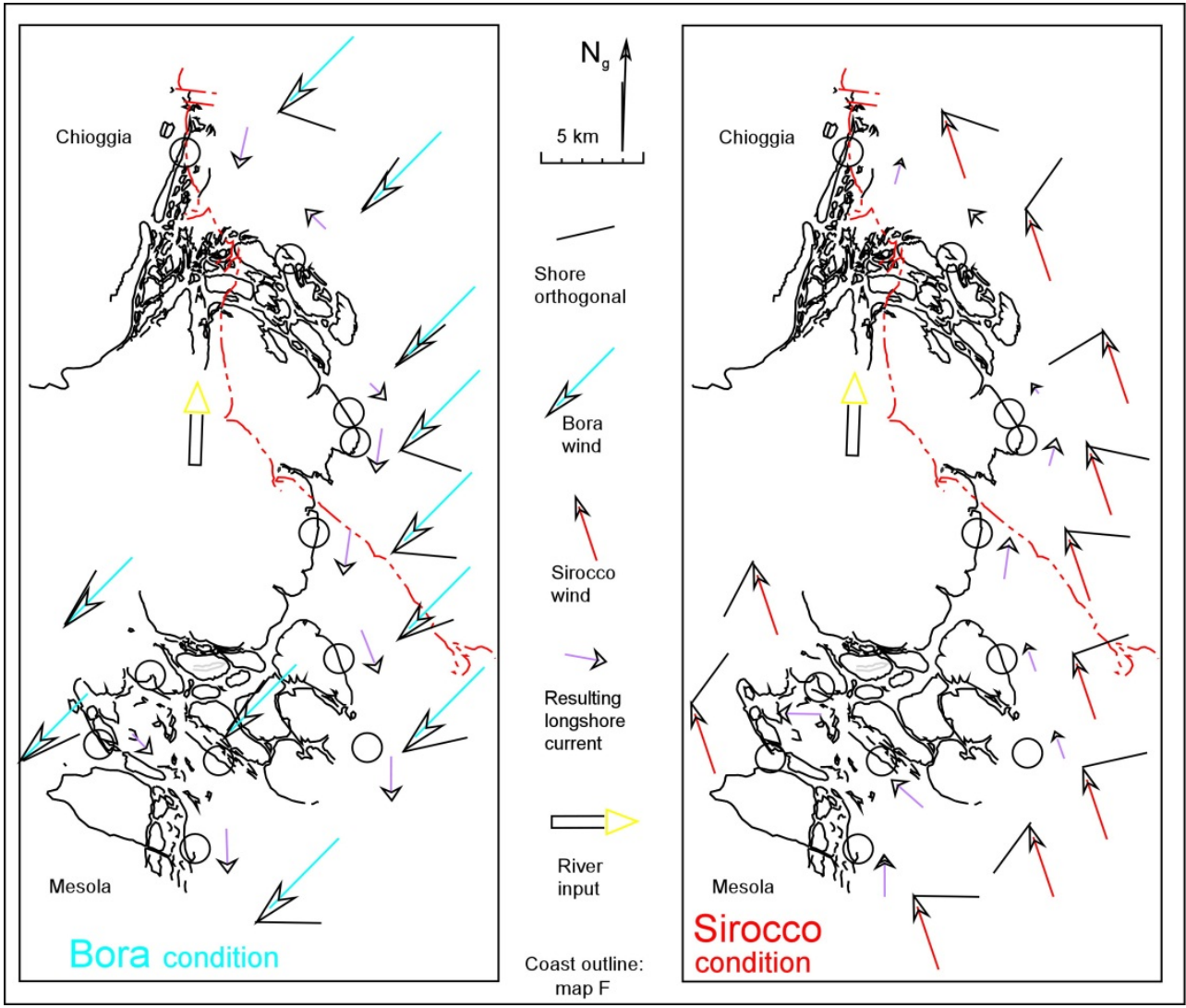

Figure 17. Long shore current directions induced by Bura and Sirocco winds on F map coastline profile (Cremonini and Samonati 2009; Cremonini 2010, Fig. 1).

\section{Conclusion}

In the study, careful recovery and analysis of some data concealed in three sixteenth century maps were done, and various technical signs preserved in them were identified and discussed. All these details show interesting information concerning the original survey performed to generate the maps, and help to comprehend the differences in the represented coastal areas among the analysed coeval maps. Notwithstanding the analysis cannot comprehensively explain all questions concerning the eroded coastal areas, due to the fact that existing landmarks cannot be found in disappeared areas, an attempt to explain the difference in the morphology of the coast was made. On the base of the recognition of a gross deformation in one map, a good example of a possible alleged author's intervention was given, attempting to restore the original appearance of the possible former map configuration. Finally, a comparison of the new product with present cartography and other coeval maps, via modern georeferencing methods, was able to support the hypothesis. 
Finally, the study shows that pre-geodetic maps usually should not be regarded as completely original technical products but rather as an assemblage of various data-sets coming from previous sources. Thus, a study of ancient cartography should start from a philological analysis of the maps (i.e. search for origin, target, models, cultural atmosphere of that time) and it should subsequently become a "stratigraphic" reading of both relationships existing among the drawing details and accidents affecting the maps. A thorough knowledge of the ancient field surveying techniques (i.e. pathways, distances, contemporaneous use of various kinds of instruments, previous cartographic sources, etc.) is essential in order to understand genesis and size of the surveying errors recorded in the map, and therefore it is also essential to direct the georeferencing techniques towards the definition of the real topography and morphology of those areas that today no longer exist, e.g. due to natural environmental processes. In other words, the technical approach to ancient cartography cannot be reduced to a simple georeferencing attempt; the georeferencing should rather act as an essential support for a deep analysis of the maps, that in this way can become a more useful tool to various classes of researchers.

\section{Author details}

Gabriele Bitelli and Giorgia Gatta

Department of Civil, Environmental and Materials Engineering (DICAM),

Alma Mater Studiorum - University of Bologna, Bologna, Italy

Stefano Cremonini

Department of Earth and Geological-Environmental Sciences, Alma Mater Studiorum - University of Bologna, Bologna, Italy

\section{Acknowledgement}

We are grateful to the Venice National Archive, for the consultation of the map by Fabri and the map by Lorini et al., and to the Engineering Faculty Library Gian Paolo Dore of the University of Bologna, for the consultation of the textbook by O. Fabri.

\section{References}

Adcock E.P, Varlamoff M.T, Kremp V (2004) Principi dell'IFLA per la cura e il trattamento dei materiali di biblioteca. Bari: IFLA (International Federation of Library Associations and Institutions).

Balletti C (2006) Georeference in the analysis of the geometric content of early maps. ePerimetron, Vol. 1, No. 1. pp 32-42. Available:

http://www.e-perimetron.org/Vol_1_1/Vol1_1.htm.

Benavides J., Koster E. (2006) Identifying surviving landmarks on historical maps, ePerimetron, Vol. 1, No. 3. pp 287-296. Available:

http://www.e-perimetron.org/Vol_1_3/Vol1_3.htm. 
Bitelli G, Cremonini S, Gatta G (2010) Late Renaissance survey techniques revealed by three maps of the old Po river delta. E-perimetron, Vol. 5, No. 3. pp 172-175. Available: http://www.e-perimetron.org/Vol_5_3/Vol5_3.htm.

Bitelli G, Cremonini S, Gatta G (2009) Ancient maps comparisons and georeferencing techniques: a case study from the Po river delta (Italy). e-Perimetron, Vol. 4, No. 4. pp 221-228. Available:

http://www.e-perimetron.org/Vol_4_4/Vol4_4.htm.

Boutoura C, Livieratos E (2006) Some fundamentals for the study of the geometry of early maps by comparative methods. e-Perimetron, Vol. 1, No. 1. pp 60-70. Available: http://www.e-perimetron.org/Vol_1_1/Vol1_1.htm.

Cremonini S (2007a) Questioni di geomorfologia costiera del delta del Po anteriormente al 1604. Evidenze dalla cartografia storica. In: Annali di Ricerche e Studi di Geografia, 63, 3/4. pp. 5367.

Cremonini S. (2007b) Some remarks on the evolution of the Po River plain (Italy) over the last four millennia. In: Marabini F., Galvani A., Ciabatti M. eds., China-Italy bilateral symposium on the coastal zone: evolution and safeguard, Bologna 4-8 November 2007. pp. 17-24.

Cremonini S, Samonati E (2009) Value of ancient cartography for geoenvironmental purposes. A case study from the Po river delta coast (Italy). In: Geografia, Fisica e dinamica del Quaternario, No. 32. pp 135-144.

Cremonini S. (2010) Climatic suggestions from the Po River delta coastline (Italy) at the beginning of the Little Ice Age. Proceedings of the China-Italy Bilateral Symposium on the coastal Zone and continental shelf evolutional trend, Bologna, October 5-8, 2010. pp. $114-119$

Fabri O (1673) L'uso della squadra mobile. Con la quale per teoria et per pratica si misura geometricamente ogni distanza, altezza, e profondità. S'impara à perticare, liuellare, et pigliare in dissegno le Città, Paesi, et Provincie. [...]. Padova: Gattella.

Jenny B, Hurny L (2011) Studying cartographic heritage: analysis and visualization of geometric distortions. Computers \& Graphics 35-2. Elsevier. pp 402-411.

Livieratos E (2006) On the Study of the Geometric Properties of Historical Cartographic Representations. Cartographica, Vol. 41, issue 2. pp. 165-175.

Martini A. (1883) Manuale di metrologia, ossia misure, pesi e monete in uso attualmente e anticamente presso tutti i popoli. Torino: Loescher.

Panepinto E (2009) Ottavio Fabri, Perito et Ingegnero Publico. Degree thesis on European History and Geography. University of Verona, Faculty of Arts and Philosophy. 